\title{
Peningkatan Pengetahuan Lansia Melalui Penyuluhan Kesehatan Reproduksi Pada Lansia Pre-Menopause di Desa Sumberejo Kecamatan Banyuputih
}

\author{
Irma Noervadila ${ }^{1)}$, Yesi Puspitasari ${ }^{\text {2) }}$, Lisma Dian Kartika S. ${ }^{3)}$, Darsih Idayani ${ }^{4)}$, \\ Ahmad Khafas Rasyidi ${ }^{5)}$ \\ ${ }_{1,2,3,4,5)}$ Sekolah Tinggi Keguruan dan Ilmu Pendidikan PGRI Situbondo \\ noervadilairma@gmail.com
}

\begin{abstract}
ABSTRAK: Perkembangan dan pertumbuhan manusia akan terhenti, sehingga berikutnya akan terjadi banyak perubahan pada fungsi tubuh manusia. Perubahan tersebut paling banyak terjadi pada wanita karena pada proses menua terjadi suatu fase yaitu fase menopause (Sasitorn, 2016). Menopause merupakan masa berhentinya menstruasi yang terjadi pada perempuan dengan rentang usia 48 sampai 55 tahun. Peristiwa Pre-menopause sering tidak menjadi perhatian bagi kebanyakan wanita karena dianggapnya sebagai peristiwa alami, sebagian kecil mengganggapnya sebagai sesuatu yang buruk, menopause juga dianggap sebagai hal yang tabu untuk dibicarakan secara terbuka. Hal ini dikarenakan dasar pengetahuan wanita tentang menopause masih sedikit sehingga wanita Pre-menopause enggan untuk mencaritahu tentang informasi tentang Pre-menopause. cara mengatasimasa menopauseketerlibatan pemerintah dan juga masyarakat dalam mengatasi masalah menopause antara lain bekerjasama dengan tim dari berbagai disiplin ilmu misalnya psikologi dan tenaga kesehatan melalui kegiatan posyandu lansia sebagai tempat efektif untuk memberikan informasi tentang Pre-menopause, menopause, dan pasca menopause. Peran bidan di komunitas diharapkan dapat memberikan konseling di wilayah kerjanya sebagai tempat yang efektif untuk memberikan informasi tentang Premenopause, menopause, dan pasca menopause.
\end{abstract}

Kata kunci : Menopause, penyuluhan Kesehatan, Pre-Menopause

\begin{abstract}
The development and growth will stop, so the next there will be many changes to the function of the human body. These changes occur most often in women because the aging process occurs in a phase, namely the menopause phase (Sasitorn, 2016). Menopause is the cessation of menstruation that occurs in women with an age range of 48 to 55 years. This period is very complex for women because it is related to their physical and mental condition. Pre-menopausal events are often not a concern for most women because they are considered a natural event, a small number consider it bad, menopause is also considered a taboo subject to be discussed openly. This is because women's basic knowledge about menopause is still small so Pre-menopausal women are reluctant to find out about information about Pre-menopause. how to overcome menopause the involvement of the government and also the community in overcoming the problem of menopause include collaborating with teams from various disciplines such as psychology and health workers through the elderly posyandu activities as an effective place to provide information about Pre-menopause, menopause, and post-menopause. The role of midwives in the community is expected to provide counseling in their work area as an effective place to provide information about Pre-menopause, menopause, and postmenopause.
\end{abstract}

Keywords: Menopause, Health education, Pre-Menopause 


\section{PENDAHULUAN}

Masyarakat adalah sejumlah manusia atau penduduk dalam arti seluas-luasnya dan terikat oleh kebudayaan, adat istiada yang bersifat continue dan terikat oleh indentitas yang sama. Jadi yang dimaksud pemberdayaan masayarakat ialah upaya meningkatkan keadaan pendudukdengan menggali potensi yang ada di masyarakat agar mereka mampu meningkatkan taraf hidup baik melalui pendidikan maupun pelatihan yang berisimotivasi, penyadaran atau penguat agar masyarakat berdaya (Mahbuban, 2016).

Menopause merupakan masa berhentinya menstruasi yang terjadi pada perempuan dengan rentang usia 48 sampai 55 tahun. Masa ini sangat kompleks bagi perempuan karena berkaitan dengan keadaan fisik dan kejiwaannya. Selain perempuan mengalami stress fisik dapat juga mengalami stress psikologi yang mempengaruhi keadaan emosi dalam menghadapi hal normal sebagaimana yang dialami oleh semua perempuan (Dewa ayu, 2013). Perubahan yang terjadi tersebut paling banyak terjadi pada wanita karena proses menua terjadi suatu fase yaitu fase menopause.

Menopause merupakan fase dimana wanita tidak mengalami menstruasi. Seringkali wanita menghadapi menopause dengan rasa cemas dan takut karena memasuki usia tua dan sudah tidak dapat melahirkan anak Akibat yang ditimbulkan dari keadaan ini menurunnya hormon estrogen, hormon progesteron dan hormon seks dapat menimbulkan gejala fisik yang mungkin dialami saat mencapai masa menopause yakni berupa rasa panas yang tiba-tiba menyerang bagian atas tubuh, keluar keringat yang berlebihan pada malam hari, sulit tidur, iritasi pada kulit, gejala pada mulut dan gigi, kekeringan vagina, kesulitan menahan buang air kecil, dan peningkatan berat badan (Intan, 2017). Perubahan keseimbangan hormonal ini dapat menyebabkan berbagai gejala psikologis ditandai dengan sikap yang mudah tersinggung, depresi, cemas, suasana hati (mood) yang tidak menentu, menurunnya kemampuan berfikir dan daya ingat. 
Materi Penyuluhan tentang Menopause

Slide 1

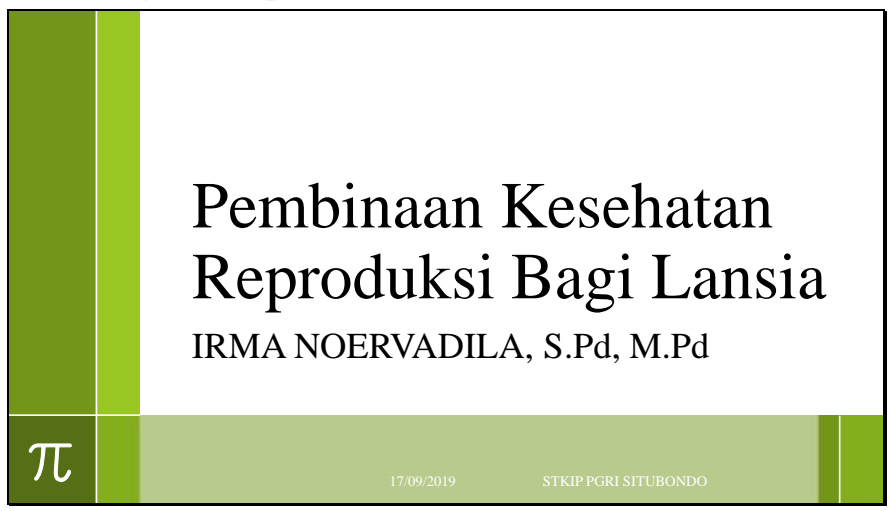

Slide 2

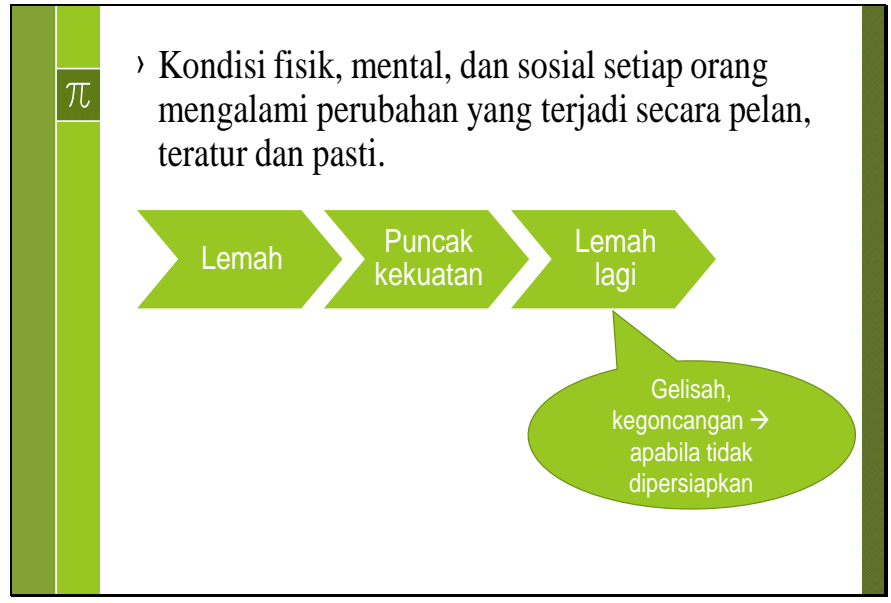

Slide 3

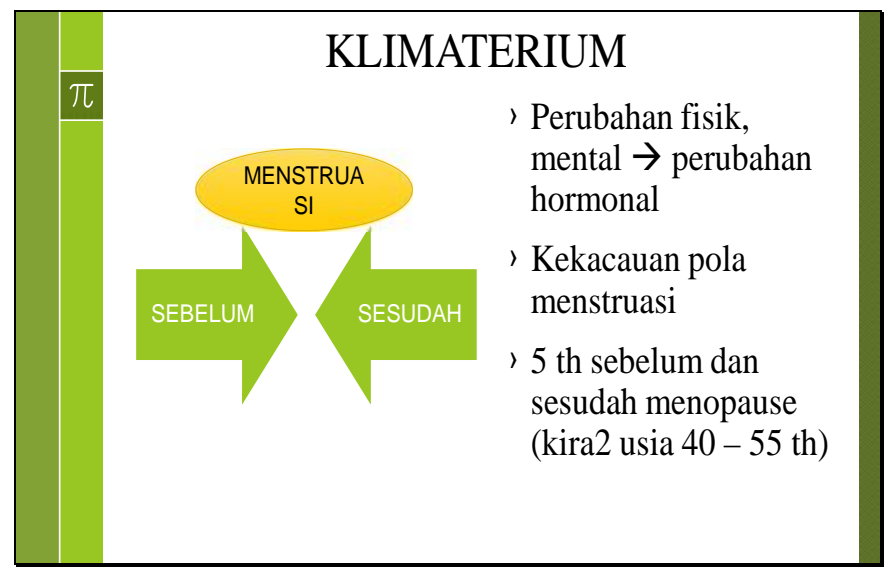


Volume 4, Nomor 1, Maret 2020

Slide 4 Kondisi Fisiologi

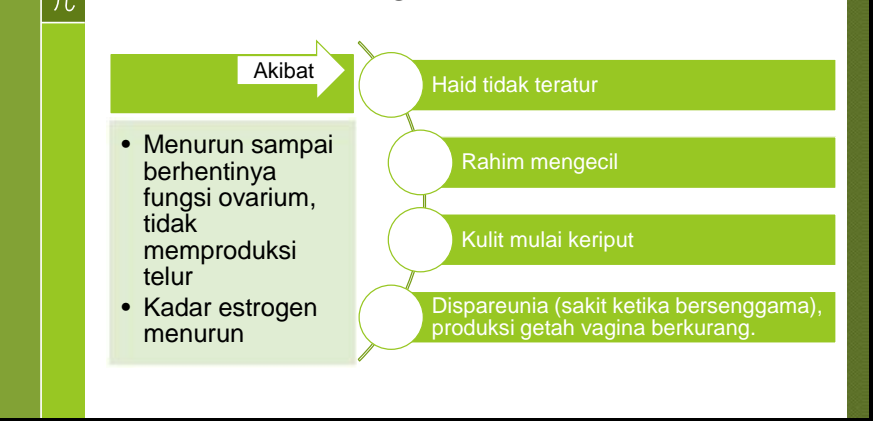

Slide 5

\begin{tabular}{|ll}
\hline$\pi \quad \begin{array}{l}\text { Gejala psikosomatis } \\
\text { meningkat }\end{array}$ & Kondisi Psikologis \\
$\square$ Cemas & $\square$ Takut tanpa sebab \\
$\square$ Gelisah & $\square$ Susah tidur \\
$\square$ Mudah tersinggung & $\square$ Gampang lelah \\
$\square$ Kesepian & $\square$ Berdebar-debar \\
$\square$ Merasa terasing & $\square$ Cemburu \\
& $\square$ Curiga pada suami \\
\hline
\end{tabular}

Slide 6

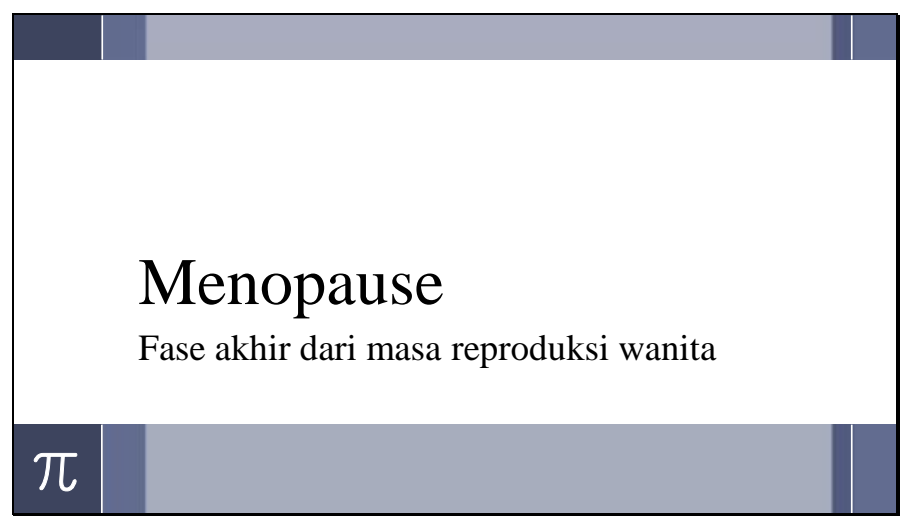


Slide 7

$\pi$ Proses Menopause

\begin{tabular}{|c|c|}
\hline \multirow{4}{*}{$\begin{array}{l}\text { Menopause } \\
\text { adalah } \\
\text { waktu } \\
\text { berhentinya } \\
\text { siklus haid } \\
\text { wanita } \\
\text { secara } \\
\text { alamiah } \\
\text { pada } \\
\text { periode usia } \\
45-50 \text { th. }\end{array}$} & 40 th Perubahan dimulai \\
\hline & 50 th Tidak haid lagi (rentang $48-52$ th) \\
\hline & Setiap wanita berbeda masanya \\
\hline & $\begin{array}{l}\text { Dipengaruhi oleh usia pertama kali haid, perbedaan } \\
\text { status, gizi, kultur atau budaya, lingkungan sosial }\end{array}$ \\
\hline
\end{tabular}

Slide 8

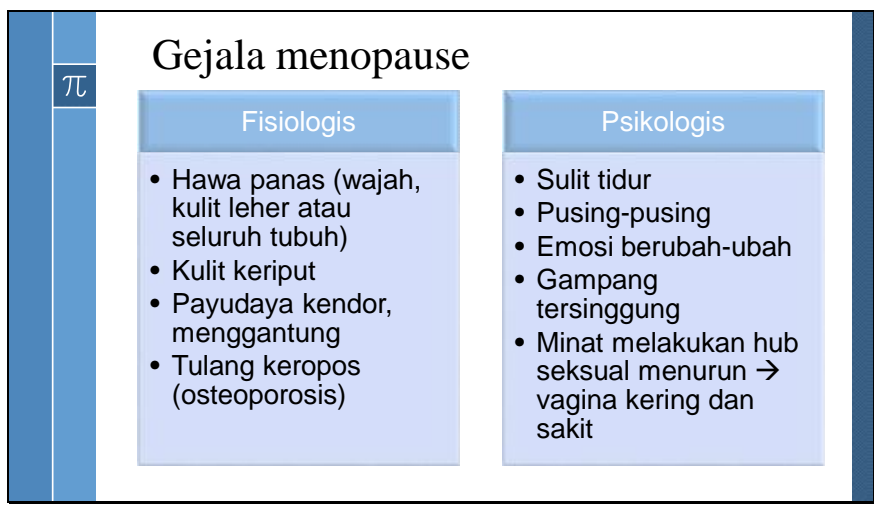

Slide 9

Menyikapi Perubahan dan Gejala yang

$\pi$ timbul saat Menopause

1.

Pengetahuan

dan

kesadaran

tentang

menopause

dan

klimaterium

pada

umumnya
2.

Keharmonisan

dan adanya

saling

pengertian

dalam

keluarga 
Volume 4, Nomor 1, Maret 2020

Slide 10

$\pi$

Menghindari Penuaan Kulit Terlalu Cepat

\begin{tabular}{c|c|c|c|}
$\begin{array}{c}\text { Usahakan } \\
\text { tubuh } \\
\text { jangan } \\
\text { terlalu } \\
\text { gemuk }\end{array}$ & $\begin{array}{c}\text { Hindari } \\
\text { sinar } \\
\text { matahari }\end{array}$ & $\begin{array}{c}\text { Tingkatkan } \\
\text { aktivitas } \\
\text { olahraga } \\
(3 \times 1\end{array}$ & $\begin{array}{c}\text { Massage }- \\
\text { pelembab } \\
\text { minggu })\end{array}$ \\
kulit \\
\end{tabular}

Slide 11

\begin{tabular}{|l|}
\hline $\begin{array}{l}\text { Mempersiapkan Diri Menghadapi } \\
\text { Menopause }\end{array}$ \\
Memenuhi makanan bergizi \\
- Menghambat implikasi negatif terhadap kinerja otak, \\
mencegah kulit mengering \\
$\begin{array}{l}\text { Jenis makanan yg mengandung phytohormon } \\
\text { estrogen } \\
\text { - Kacang kedelai, pepaya, tiap hari } \rightarrow \text { mencegah hawa } \\
\text { panas } \\
\text { - Mengandung vit. D: ikan tuna, telur, susu }\end{array}$ \\
\hline
\end{tabular}

Slide 12

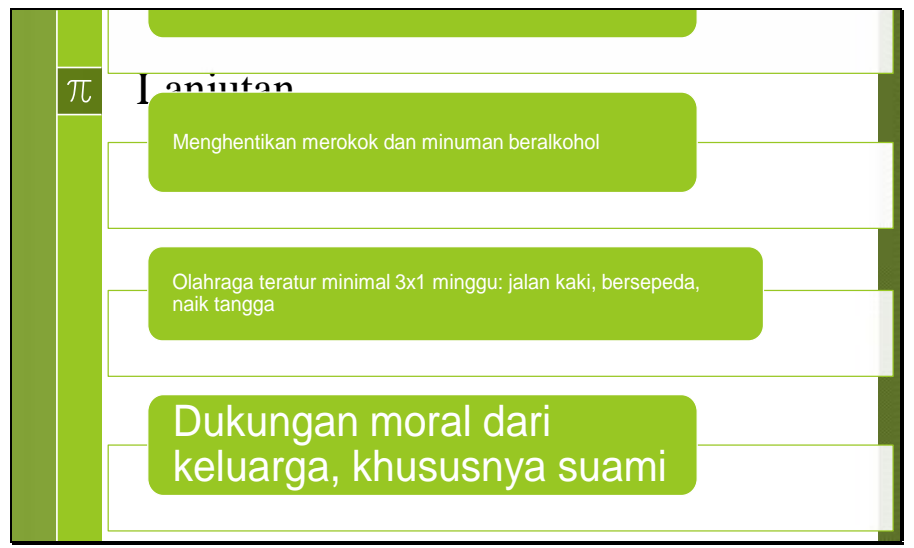


Slide 13

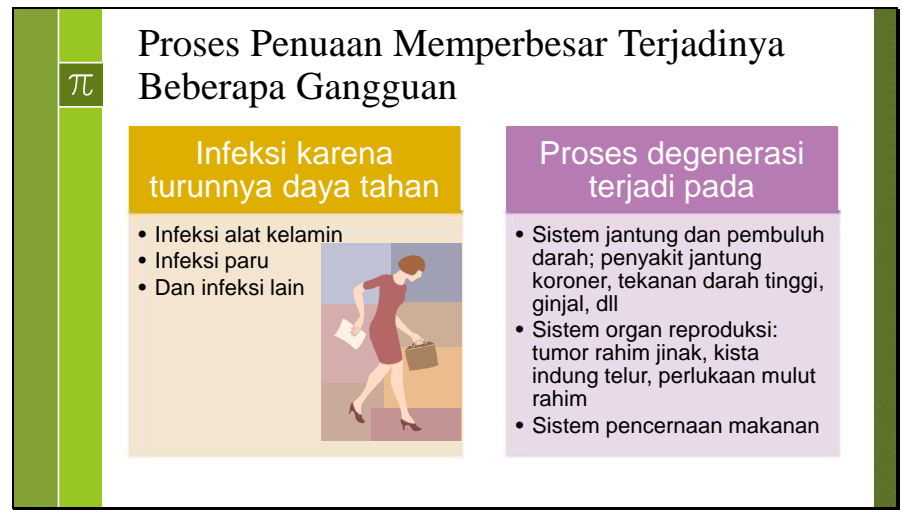

Slide 14

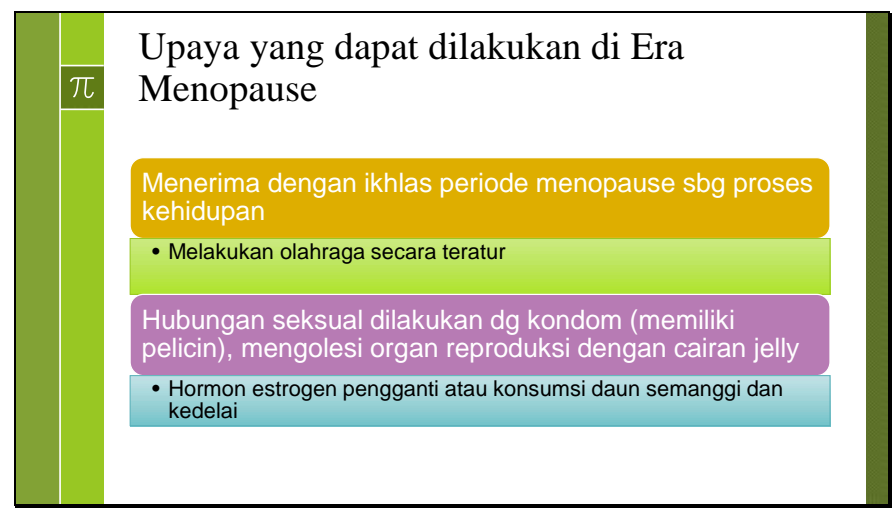

Slide 15

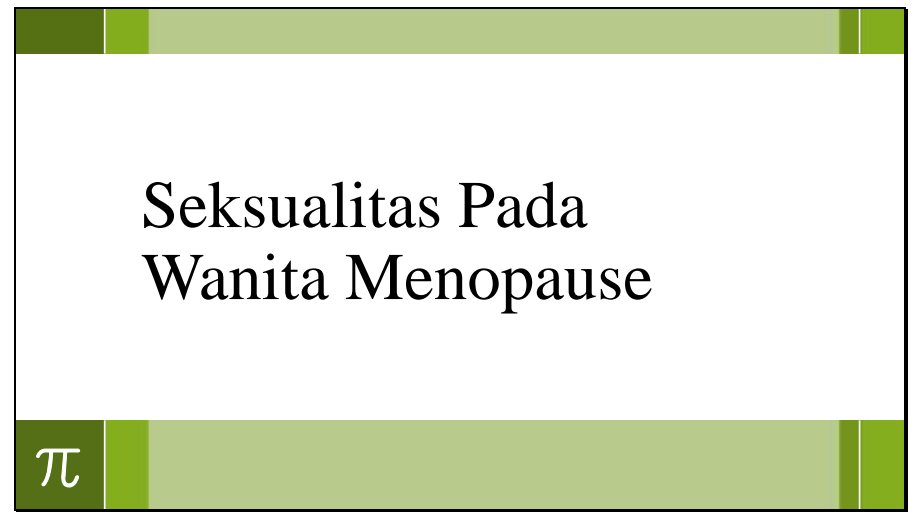


Slide 16

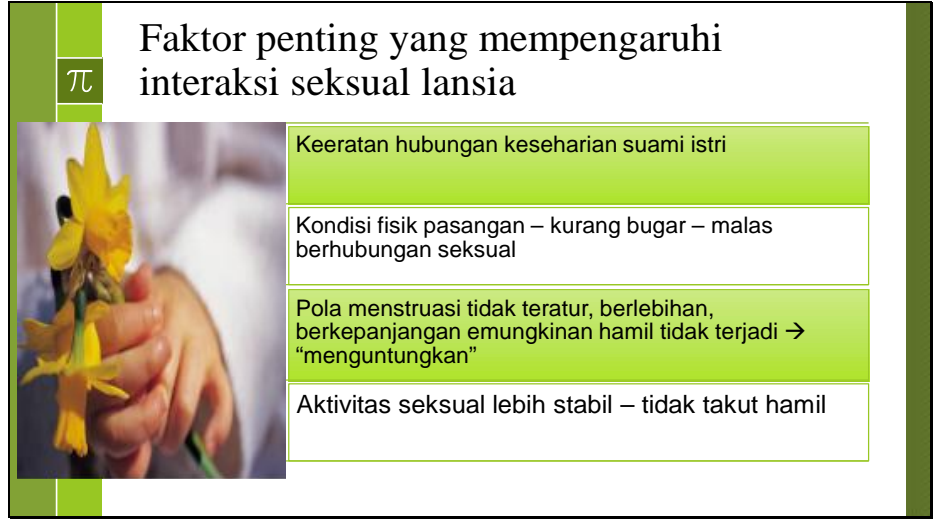

Slide 17

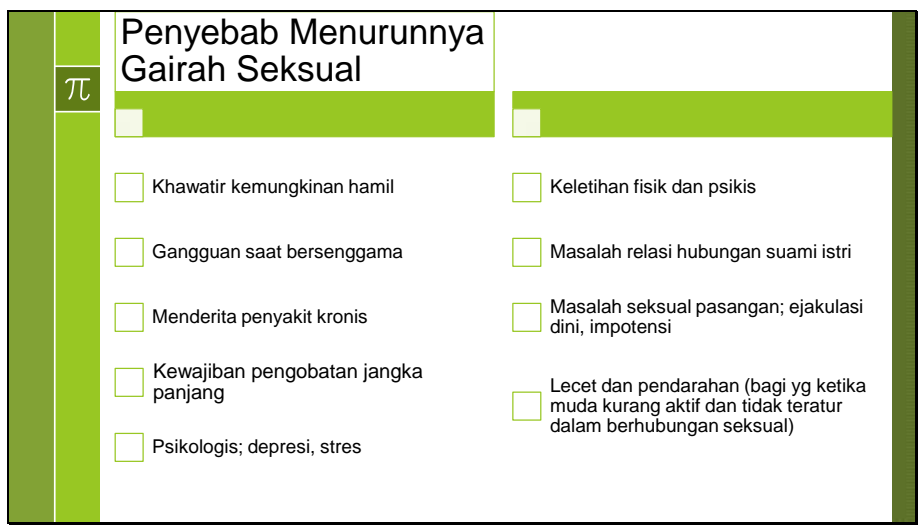

Slide 18

\begin{tabular}{|l|}
\hline$\pi \quad$\begin{tabular}{l|} 
Hubungan Seksual Pada Masa \\
Menopause
\end{tabular} \\
\hline , Aktivitas seksual sebaiknya terus \\
dipertahankan \\
, Perubahan lain: rangsangan lebih lama \\
, Mengatasi vagina kering: gunakan \\
"pelumas" misalnya sejenis gel \\
, Agar tidak bosan: variasi gaya agar \\
masing-masing menikmati
\end{tabular}


Volume 4, Nomor 1, Maret 2020

Slide 19

$\pi \quad$ Kenikmatan Seksual pada Isteri Menopause

, Kehidupan seksual menopause ditentukan oleh kehidupan seksual pada masa sebelumnya (masih muda)

> Bila tidak menyenangkan $\rightarrow$ terasa sebagai beban

Slide 20

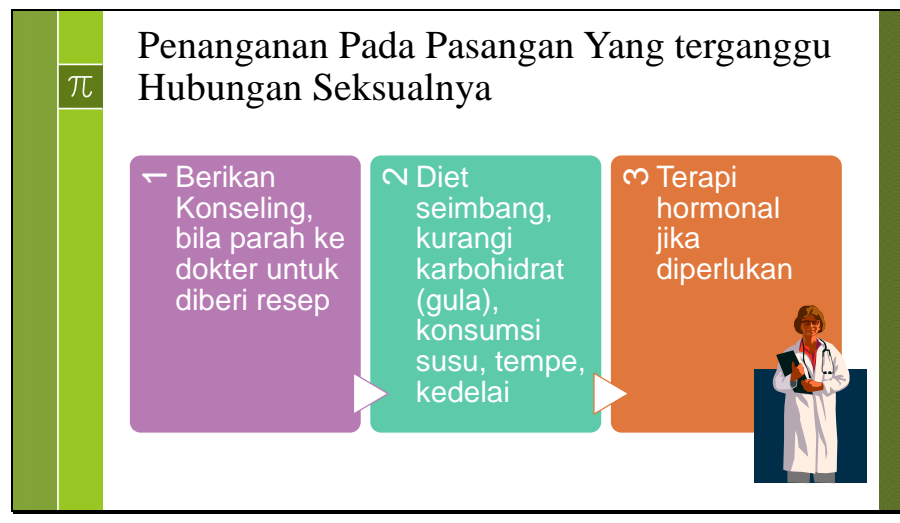

Slide 21

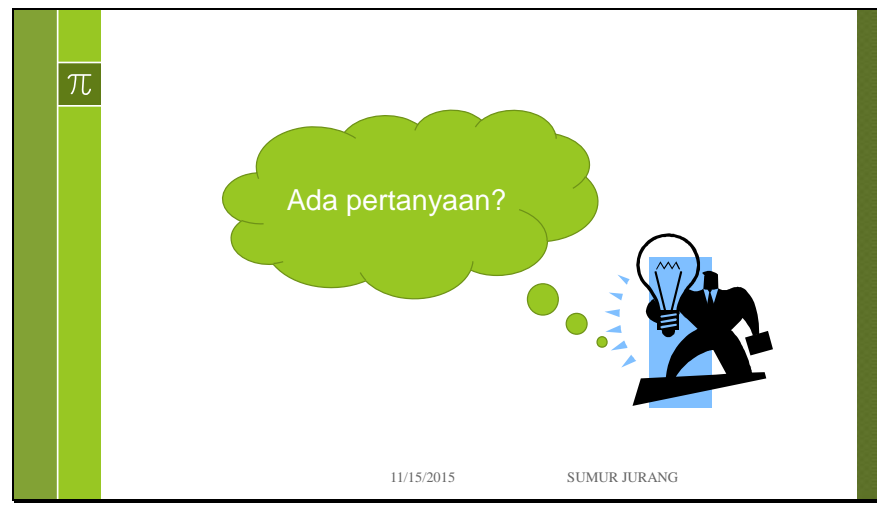




\section{METODE PELAKSANAAN}

Bentuk kegiatan pengabdian kepada masyarakat yang berjudul "Peningkatan Pengetahuan Lansia Melalui Penyuluhan Kesehatan Reproduksi Pada Lansia Premenopause di Desa Sumberejo Kecamatan Banyuputih", dilakukan secara bertahap sesuai dengan program yang telah disusun sebelumnya. Seluruh program kegiatan disusun secara bersama dalam bentuk Rencana Tindak dengan rincian berikut ini;

Tabel 1. Rencana Tindak

\begin{tabular}{|c|l|c|c|}
\hline \multirow{2}{*}{ No } & \multicolumn{1}{|c|}{ Aktivitas/Kegiatan } & \multicolumn{2}{|c|}{ Bulan } \\
\cline { 3 - 4 } & \multicolumn{1}{|c|}{} & \multicolumn{1}{|c|}{} & \multicolumn{1}{|c|}{2} \\
\hline 1 & Penyusunan rencana Kerja dan tindakan & & \\
\hline 2 & Persiapan penyuluhan & & \\
\hline 3 & Koordinasi dengan Kades dan perangkat desa Sumberejo & \\
\hline 4 & Penyebaran undangan ke warga (Ibu-ibu) & & \\
\hline 5 & $\begin{array}{l}\text { Penyuluhan Kesehatan Reproduksi Pada Lansia Pre- } \\
\text { Menopause }\end{array}$ & & \\
\hline 6 & Evaluasi Penyuluhan & \\
\hline
\end{tabular}

\section{PELAKSANAAN}

Bentuk Kegiatan penyuluhan kesehatan reproduksi pada lansia pre-menopause dilakukan melalui tahapan sebagai berikut:

1. Persiapan kegiatan meliputi:

a. Kegiatan survei tempat pengabdian kepada masyarakat yaitu di Desa Sumberejo Kecamatan Banyuputih Dusun Krajan dan Karang Rejo

b. Permohonan ijin kegiatan pengabdian masyarakat kepada Kepala desa dan pengurus Kepala Desa Sumberejo setempat

c. Pengurusan administrasi (surat-menyurat)

d. Persiapan alat dan bahan serta akomodasi

e. Persiapan tempat untuk penyuluhan yaitu menggunakan aula di Kantor Kepala Desa Sumberejo.

2. Kegiatan pendidikan kesehatan (penyuluhan) meliputi:

a. Pembukaan dan perkenalan dengan ibu-ibu dari dusun Krajan dan Karang Rejo yang hadir di acara penyuluhan

b. Penyuluhan mengenai pengenalan pre-menopauseyang berkenaan dengan proses biologis yang menandai berakhirnya masa subur seorang wanita, dampaknya terhadap kesehatan baik fisik maupun psikis dan mengetahui gejala-gejalanya serta bagaimana cara menghadapi menopause pada lansia.

c. Sesi diskusi/tanya jawab dengan peserta penyuluhan kesehatan reproduksi pada lansia pre-menopause 
3. Penutupan
a. Kegiatan ditutup dan diakhiri dengan bacaan do'a oleh perwakilan Kepala desa Sumberejo.
b. Foto bersam dengan peserta penyuluhan
c. Berpamitan dengan pengurus dan Wakil Kepala desa Desa Sumberejo Kecamatan Banyuputih Ds. Krajan dan Ds. Karang Rejo.
d. Pembuatan laporan kegiatan pengabdian Kepada Masyarakat.

\section{HASIL DAN LUARAN}

Output yang didapat dalam kegiatan pengabdian kepada masyarakat ini diantaranya adalah:

1. Ibu-ibu Lansia dari Desa Sumberejo diberikan pendidikan kesehatan (penyuluhan) mengenai pengenalan masa pre-menopause, gejala gejala yang terjadi pada masa pre-menopause dan bagaimana cara mengatasinya

2. Dari hasil penyuluhan, ibu-ibu lansia memahami mengenai isi materi penyuluhan dan diakhir sesi diberikan waktu untuk tanya jawab.

Sedangkan outcome yang didapatkan dari kegiatan penyuluhan ini antara lain:

1. Dengan adanya kegiatan pengabdian kepada masyarakat yang berupa penyuluhan mengenai kesehatan reproduksi pada lansia pre-menopausedapat meningkatkan pengetahuan ibu-ibu lansia tentang pengertian pre-menopause, gejala-gejala menopause, dampak menopause terhadap kesehatan fisik dan psikis, dan cara menghadapinya. Selain itu diharapkan dapat meningkatkan kesiapanibu-ibu rumah tangga di Desa Sumberejo Kabupaten Banyuputih dalam menghadapi Pre-menopause.

2. Lebih jauh, diharapkan kegiatan-kegiatan serupa dapat berdampak pada peningkatan kesiapan ibu-ibu rumah tangga di Desa Sumberejo Kabupaten Banyuputih dalam menghadapi Pre-menopause.

3. STKIP PGRI Situbondo semakin dikenal sebagai institusi yang mempunyai kepedulian terhadap permasalahan-permasalahan masyarakat disekitar, tidak hanya pada generasi muda namun juga pada kesejahteraan lansia. 


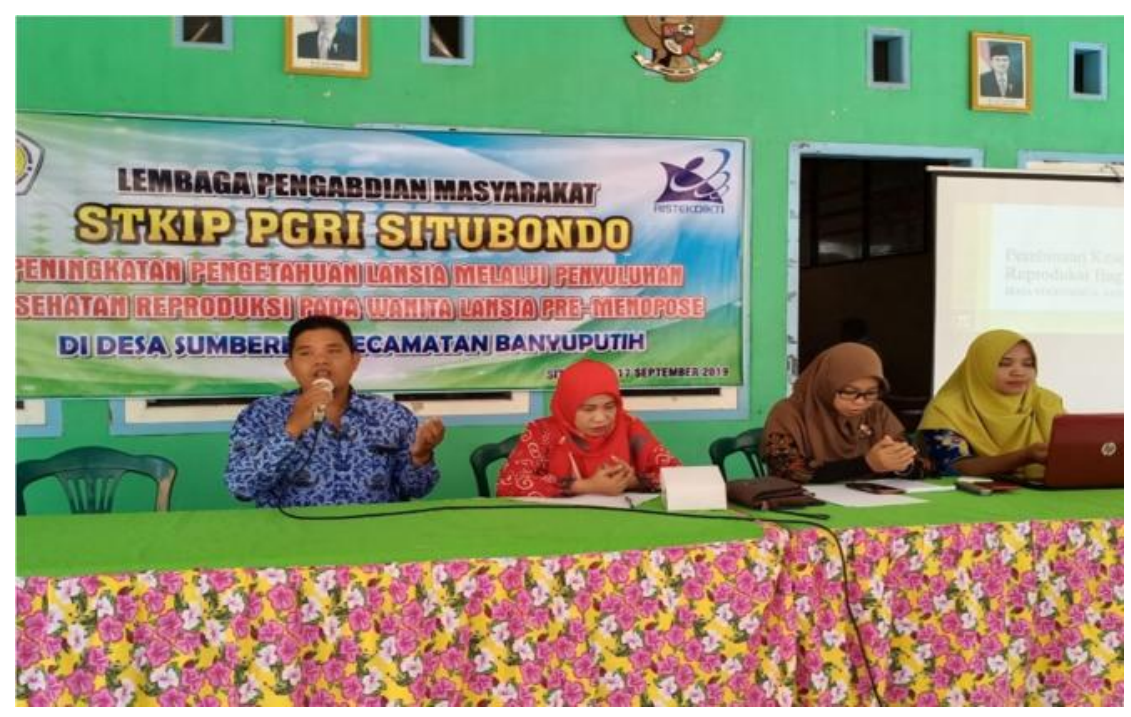

Gambar 1. Pelaksanaan Sosialisasi

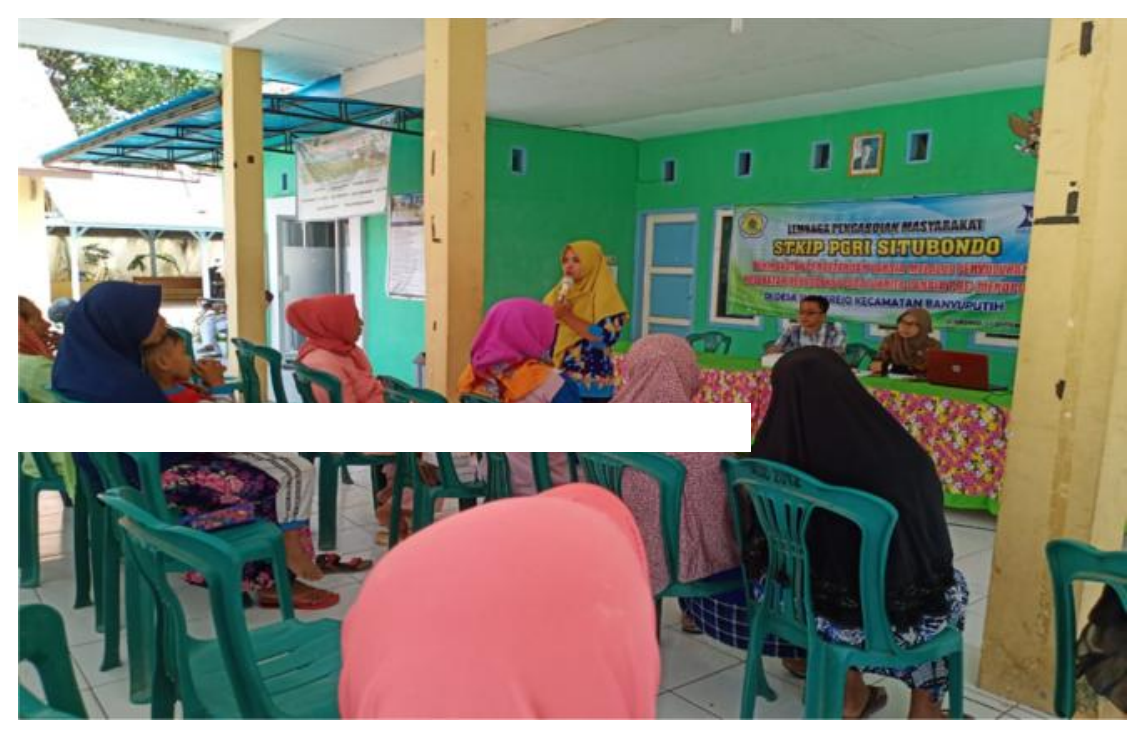

Gambar 2. Bersama peserta sosialisasi

Kegiatan penyuluhan kesehatan reproduksi pada lansia pre-menopause di Desa Sumberejo Kecamatan Banyuputih secara umum berjalan dengan lancar. Wakil Kepala Desa dan seluruh pengurus di Kepala Desa Sumberejo dengan senang hati bersedia membatu pelaksanaan kegiatan penyuluhan ini, sehingga kegiatan penyuluhan tidak mengalami kendala yang besar. Tempat yang digunakan untuk kegiatan adalah aula Kantor Kepala Desa Desa Sumberejo, Kecamatan Banyuputih di Situbondo.

Kegiatan inti yaitu pemberian materi penyuluhan berlangsung selama kurang lebih 45 menit dan diakhir sesi pemateri memberikan waktu untuk diskusi terkait isi materi penyuluhan yang telah disampaikan. Didapatkan 3 pertanyaan dari peserta 
penyuluhan yang terdiri dari ibu-ibu lansia dengan kisaran umur 40 sampai 60 tahun. Setelah menjawab pertanyaan dari peserta, pemateri melakukan evaluasi terkait materi yang telah disampaikan dengan cara memberikan pertanyaan pada peserta dan mempersilahkan peserta untuk menjawab pertanyaan tersebut. Peserta yang mampu menjawab diberi applause sehingga peserta merasa senang dan ibu-ibu yang lain bersemangat untuk menjawab. Setelah sesi diskusi berakhir dilanjutkan sesi penutupan yang diakhiri pembacaan doa oleh wakil dari Kepala Desa Sumberejo.

Adapun kendala yang dihadapi dalam pelaksanaan kegiatan ini adalah pada tahap persiapan yaitu pembagian undangan kepada warga dusun Krajan dan Karang Rejo. Adanya perbedaan waktu luang warga serta tempat yang lumayan sulit di jangkau sehingga pelaksana yang dibantu oleh pengurus Kepala Desa Sumberejo, cukup kesulitan pada saat membagikan undangan kepada warga Dusun Krajan dan Dusun Karang Rejo. Diharapkan ada kegiatan yang berkelanjutan sehingga semakin dapat meningkatkan pengetahuan lansia khususnya ibu-ibu rumah tangga.

Berdasarkan pelaksanaan kegiatan Pengabdian Kepada Masyarakat, maka dapat disimpulkan bahwa:

1. Kegiatan pengabdian kepada masyarakat mengenai pendidikan kesehatan (penyuluhan) tentang kesehatan reproduksi pada lansia pre-menopause yang berlangsung di Desa Sumberejo Kecamatan Banyuputih, Situbondo telah terlaksana dengan baik.

2. Kegiatan pengabdian kepada masyarakan mengenai kesehatan reproduksi pada lansia pre-menopause mendapat respon yang baik dari para peserta yang terdiri dari ibu-ibu lansia warga Dusun Krajan dan Dusun Karang Rejo.

\section{KESIMPULAN}

Berdasarkan pelaksanaan kegiatan Pengabdian Kepada Masyarakat, maka dapat disimpulakan bahwa:

1. Kegiatan pengabdian kepada masyarakat mengenai pendidikan kesehatan (penyuluhan) tentang kesehatan reproduksi pada lansia pre-menopause yang berlangsung di Desa Sumberejo Kecamatan Banyuputih, Situbondo telah terlaksana dengan baik.

2. Kegiatan pengabdian kepada masyarakan mengenai kesehatan reproduksi pada lansia pre-menopause mendapat respon yang baik dari para peserta yang terdiri dari ibu-ibu lansia warga Dusun Krajan dan Dusun Karang Rejo.

Kegiatan pengabdian kepada masyarakat serupa dapat dilakukan secara rutin dilokasi yang sama dengan tema yang berbeda dengan sasaran masyarakat yang benarbenar membutuhkan pelayanan kesehatan khususnya lansia. 


\section{DAFTAR PUSTAKA}

Dewa Ayu .A.P. 2013. Pengaruh Pendidikan Kesehatan Terhadap Sikap Menghadapi Menopause Pada Ibu Pre-menopause Di Dukuh Ngebel Tamantirto Kasihan Bantul Yogyakarta. Skripsi. Sekolah Ilmu Keperawatan Sekolah Tinggi Ilmu Kesehatan Jenderal Achmad Yani Yogyakarta

Firda.F dan M. Ridwan. 2014. Hubungan Usia Melahirkan Terakhir, Riwayat Pemakaian Kontrasepsi, Menarche Dan Budaya Dengan Menopouse Di Kel. Mulyosari Kec. Metro Barat. Jurnal Kesehatan Metro Sai Wawai Volume VII No.1 Edisi Juni 2014, ISSN: 19779-469X.

Intan. N.H. 2017.Hubungan Tahapan Menopause Pada Wanita Dengan Tingkat Kecemasan Di Desa Karangtanjung Alian Kebumen. Sekolah Tinggi Ilmu Kesehatan Muhammadiyah Gombong.

Mahbuban. 2016. Pemberdayaan Masyarakat Melalui Bank Sampah Studi pada Bank Sampah Sinar Lestari RW 09 kepala desa Sorosutan, KecamatanUmbulharjo, Yogyakarta. Skripsi. State Islamic University Kalijagat Yogyakarta.

Maria. T. W. 2011. Pengaruh Pendidikan Kesehatan Terhadap Pengetahuan Dan

Kecemasan Pada Wanita Pre Menopause Di Desa Jendi Kecamatan Selogiri Kabupaten Wonogiri. Tesis. Univeritas Sebelas Maret Surakarta

Nirwana Laeli. 2017. Pengaruh Penyuluhan Tentang Pre-menopause Terhadap Tingkat Pengetahuan Dan Sikap Pada Ibu Pre-menopause Di Dusun Cambahan Nogotirto Gamping Sleman Yogyakarta. Naskah Publikasi. Universitas 'Aisyiyah Yogyakarta.

Nuningsih. 2012. Hubungan Tingkat Pengetahuan Tentang Monopause Dengan Keluhan Wanita Saat Monopause Di kepala desa Cijantung Kecamatan Pasar Rebo Jakarta Timut Tahun 2012.

Sasitorn Rakkuea. 2016. Gambaran Pengetahuan Wanita Tentang Menopause Di

Dukuh Sorobaon Kekepala desaan Jati Kecamatan Jaten Kabupaten Karangayar.

Vika Aprilia.S. dan Yuli Isnaeni. 2012. Pengaruh Penyuluhan Kesehatan Tentang Menopause Terhadap Kesiapan Menghadapin Menopause Pada Wanita Usia 40 Tahun ke Atas Di Dusun Kempleng Karang Sewu Galur Kulon Progo. Skripsi. PSIK STIKES Aisyiyah Yogyakarta. 